\title{
Endoscopic Management of Intraventricular Neurocysticercosis
}

\author{
Mohammad KAIF ${ }^{1}$, Mazhar HUSAIN², Bal Krishna OJHA ${ }^{3}$ \\ ${ }^{1}$ Dr. Ram Manohar Lohia Institute of Medical Sciences, Department of Neurosurgery, Lucknow, India \\ ${ }^{2}$ Sahara Hospital, Viraj Khand, Gomtinagar, Neurosurgery Clinic, Lucknow, India \\ ${ }^{3}$ King George's Medical University, Department of Neurosurgery, Lucknow, India
}

\section{ABSTRACT}

AIM: To evaluate the technique and outcome of endoscopic management of intraventricular neurocysticercosis (NCC).

MATERIAL and METHODS: We retrospectively analysed the records of 30 consecutive patients of intraventricular (intra-third and fourth ventricle) NCC who underwent endoscopic management. The clinical profiles of the patients were evaluated which included age, symptoms and signs. Transcranial endoscopy was performed through a frontal burr hole using a Gaab Universal Endoscope system with rigid $0^{\circ}$ and $30^{\circ}$ telescope for endoscopic third ventriculostomy and removal of the cyst was described. The mean follow-up period was 22.6 months.

RESULTS: In $86.67 \%$ (26/30) patients we are able to visualize/excise/decompress the cyst. We were able to successfully excise all the third ventricular cysts (16/16) and in $66.67 \%(8 / 12)$ of the fourth ventricular cysts. In $90 \%(27 / 30)$ patients we were able to successfully divert the CSF flow and achieve long-term shunt free period.

CONCLUSION: We found that endoscopic cerebrospinal fluid (CSF) diversion in cases of intraventricular NCC is feasible and associated with high success rate. Endoscopic CSF diversion in NCC related hydrocephalus usually produces a long-term cure.

KEYWORDS: Intraventricular, Neurocysticercosis, Neuroendoscopy

\section{INTRODUCTION}

$\mathrm{S}$ urgical excision of an intraventricular cysticercal cyst and restoration of the cerebrospinal fluid (CSF) flow is the main goal in the treatment of intraventricular neurocysticercosis (NCC) $(1-3,21)$. Many authors have reported their experience with endoscopic management of cases of NCC, but with fewer cases $(1,3,4,19,20)$. In this study, we present our experience with managing unusual manifestations of NCC such as hydrocephalus and intraventricular cysticercal cysts by endoscopic third ventriculostomy (ETV), cyst removal, septum pellucidotomy and decompression of the cyst.

\section{MATERIAL and METHODS}

\section{Patient Population}

This study is a retrospective analysis of 30 consecutive patients with intraventricular NCC admitted to the Department of Neurosurgery in a tertiary-care teaching hospital from March 1996 to July 2014. The mean age was 28.63 years (range 6 to 85 years) and included 19 males and 11 females.

\section{Follow-up}

The follow-up ranged from 3 months to 7 years with a mean of 22.6 months. During follow-up, the patients were evaluated clinically, and routine computed tomography/magnetic resonance imaging (CT/MRI) was done 3 months after surgery. 


\section{Operative Indication}

The main aims of the operative procedure were two. The first objective was to restore the CSF pathway while avoiding the need for a shunt device. This included ETV, septostomy and removal or decompression of the cyst. The second objective was to remove the cyst, followed by histopathological confirmation.

\section{Operative Technique}

Under monitored anaesthesia with sedation or general anaesthesia, the patients were placed supine and their head was slightly flexed and fixed in a head rest or horseshoe frame. The Gaab endoscope (Karl Storz, Germany) was used (the working sheath having an outer diameter of $6.5 \mathrm{~mm}$, working channels of $1 \mathrm{~mm}$ and $2.7 \mathrm{~mm}$ and 0 and 30-degree telescopes of $2.7 \mathrm{~mm}$ and $4 \mathrm{~mm}$ diameters, respectively). The endoscope was attached to a TV monitor and camera for visual control. We followed the surgical techniques described by Gaab and Schroeder (7). A burr hole was made, as per the information obtained from CT or MRI scans, and a transcortical approach was used to enter the ventricle. After incising the dura, the working sheath with the trocar was introduced freehand and fixed to the table by an endoscope holder (Aesculap, Germany). Next, the trocar was removed, and the rigid $30 \% 0^{\circ}$ telescope was introduced. Cystic lesions were identified and an angiographic catheter was passed through the working channel and negotiated to the cyst wall. A $5 \mathrm{ml}$ syringe was used to apply negative pressure at the cyst on the other end of the angiographic catheter. Using this negative pressure, the cyst was aspirated up to the internal opening of the working channel in the sheath with simultaneous withdrawal of the telescope assembly. The cyst was then removed using a grasper under direct vision (Figure 1A-E).
Those cysts whish were adhered were opened and coagulated using electrocautery, and their contents were aspirated. To maintain a clear view, continuous irrigation with ringer lactate solution was used. Ringer lactate solution was used for irrigation whenever bleeding was experienced. A very high increase in intracranial pressure (ICP) was avoided by maintaining inflow at permissible pressure (about $10 \mathrm{ml} / \mathrm{min}$ ) with sufficient outflow of irrigating fluid. Copious irrigation or suction was used to remove any clots. At the end of the procedure, the operating sheath was removed with the endoscope inside to look for active bleeding in the puncture channel. The burr hole was packed with a Gelfoam ${ }^{\circledR}$ piece and the skin was closed using interrupted sutures.

All the patients were given an injection of dexamethasone for 3 days and tab albendazole at $15 \mathrm{mg} / \mathrm{kg} /$ day in divided doses for 21 days.

The stoma of the ETV was made anterior to the mammillary body in the region of the tuber cinereum with an angiographic catheter, and it was dilated $1 \mathrm{~mm}$ with a Fogarty catheter (no. 3 French) (Figure 2A-E) (8). Similarly, if needed, septostomy was performed using a bipolar electrosurgical probe and a Fogarty catheter.

\section{RESULTS}

\section{Presenting Symptoms}

All the patients presented with symptoms related to hydrocephalus, which included headache, nausea, vomiting, decreased vision, diplopia and dizziness, with headache being the most common symptom.
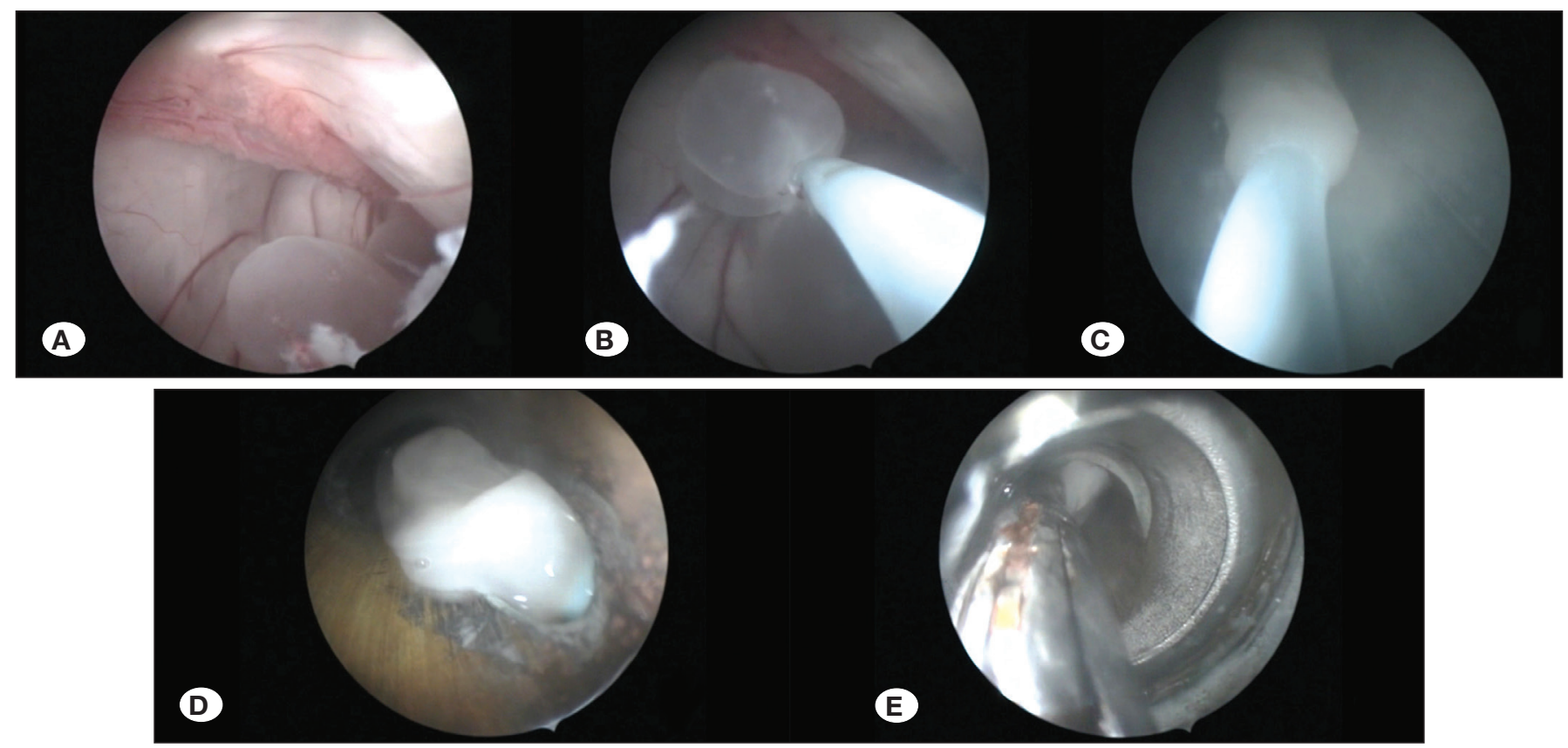

Figure 1: A) Cysticercal cyst being visualised; B) angiographic catheter negotiated to cyst; C) cyst being aspirated through the sheath under negative pressure; D) cyst brought up to the internal orifice of the sheath; E) cyst being removed with grasper through the sheath. 


\section{Presenting Sign}

The most common sign was papilledema followed by ataxia and sixth nerve palsy. The other symptoms included nystagmus, dysmetria, impaired consciousness, Parinaud syndrome and third-nerve palsy.

\section{Radiological Findings}

CT scan was available for all 30 patients, whereas MRI was available only for 4 patients, and hydrocephalus was the most common finding. Of these 30 patients, 19 patients had symptoms suspicious of intraventricular cyst, based on the radiological findings.

\section{Cyst Excision/Decompression}

We encountered an intra-third ventricle cyst, most commonly followed by fourth ventricle cyst. ETV was performed in 29 patients. In one patient with an entrapped temporal horn, a direct approach to the encysted temporal horn from the temporal cortex was taken, and the cyst was decompressed and removed. In this patient, ETV was neither attempted nor necessary. Excision of the cyst was performed in 22 cases. Details of these procedures are included in Table I.

In 26/30 patients, we are able to visualise, excise and decompress the cyst (Table II). In 27/30 patients, we were able to divert the CSF flow successfully and achieve a long-term, shunt-free period (Table III). We were able to successfully excise all the third ventricular cysts and 8/12 of the fourth ventricular cysts (Figures 3A, B; 4A, B).

\section{Outcome in Different Age Groups}

Paediatric age group: In all of our paediatric age group patients, we were successfully able to restore the CSF flow and achieve excision, decompression and visualisation of the cyst (Table IV).

Adult Patients: In 18/21 patients of the adult age group, we were successfully able to restore the CSF and, in $17 / 21$, to excise, decompress and visualise the cyst (Table V).

\section{Reasons for Failures}

Reasons for failures of endoscopic CSF diversion: Successful CSF diversion could not be achieved in three patients. One of the failure cases had a third ventricular cyst that was densely adhered to the ependymal lining of the third ventricle with marked cicatrisation. The cyst could not be excised totally; therefore, a biopsy was performed, and

Table I: Neuroendoscopic Procedures

\begin{tabular}{lc}
\hline Procedure & Number of cases \\
\hline ETV only & 4 \\
\hline ETV with excision of cyst & 22 \\
\hline ETV with decompression of cyst & 2 \\
\hline ETV with visualization of cyst & 1 \\
\hline Septostomy* & 3 \\
\hline $\begin{array}{l}\text { Aqueductoplasty\# } \\
\text { Communication of entrapped temporal } \\
\text { horn into the ventricular system with cyst } \\
\text { decompression }\end{array}$ & 2 \\
\hline
\end{tabular}

*in patients with blocked foramen of Monro.

\#in patients with fourth-ventricle cyst with narrow aqueduct.
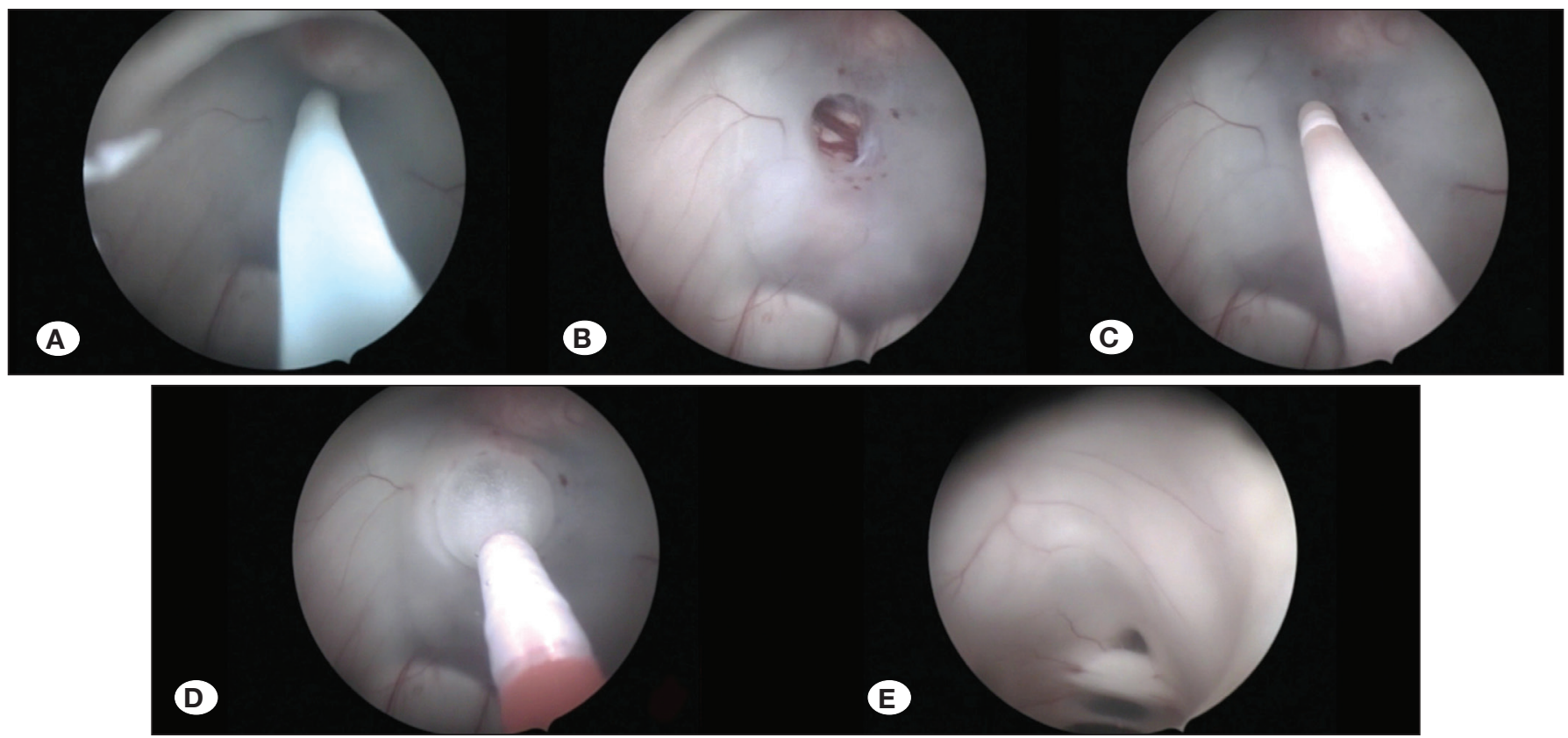

Figure 2: A) Third ventriculostomy being performed with the help of angiographic catheter; B) ETV stoma; C) Fogarty catheter inside the ETV stoma; D) stoma being dilated with Fogarty catheter; E) inspection of aqueduct. 
ETV was done. The patient remained well for three weeks; he was re-admitted after three weeks with the signs and symptoms suggestive of hydrocephalus. His CT scan showed persistence of hydrocephalus for which he underwent a ventriculoperitoneal (VP) shunt.
The other patient had a cyst in the fourth ventricle that could not be visualised during endoscopic surgery. Although an ETV was performed on this patient, he developed hydrocephalus and required a VP shunt 10 days later.

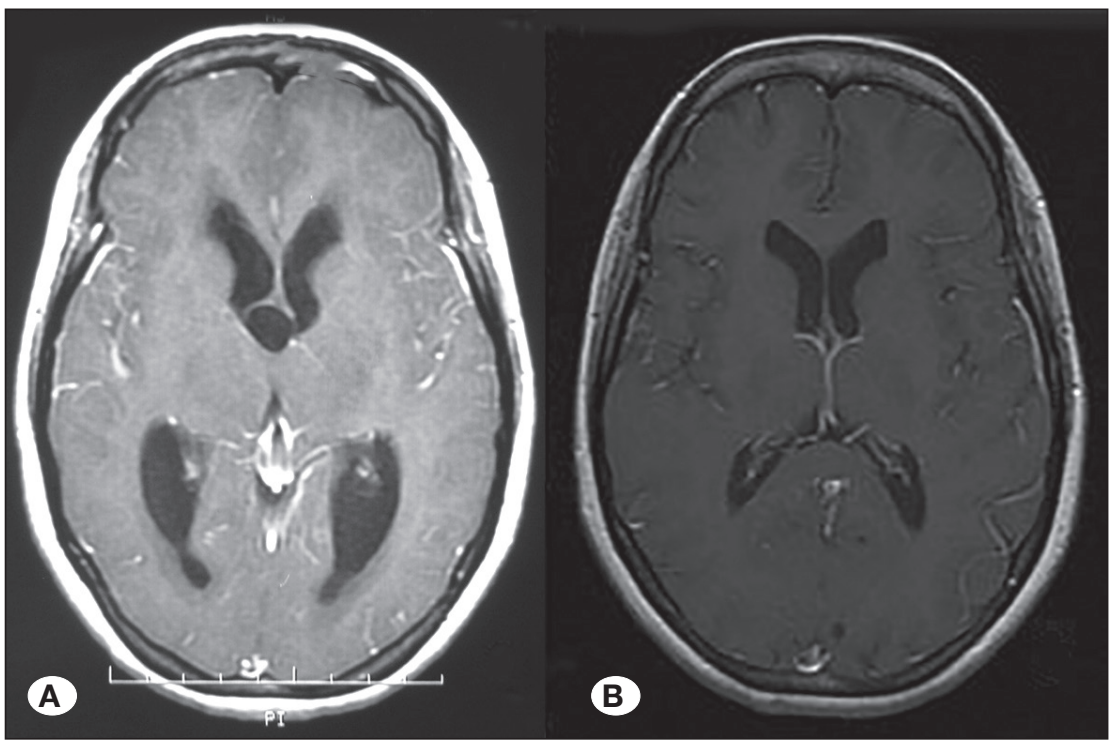

Figure 3: A) Contrast-enhanced T1-weighted axial MRI scan showing third-ventricular cyst, B) contrast-enhanced T1-weighted axial MRI scan of the same patient, showing no thirdventricular cyst.
Table II: Overall Successful Visualization/Excision/Decompression of Intraventricular Cyst

\begin{tabular}{lcc}
\hline Location & No. of cases & Percentage \\
\hline Third ventricular NCC & $16 / 16$ & $100 \%$ \\
\hline Fourth ventricular NCC & $8 / 12$ & $66.67 \%$ \\
\hline Temporal horn NCC & $1 / 1$ & $100 \%$ \\
\hline Septum Cavum NCC & $1 / 1$ & $100 \%$ \\
\hline
\end{tabular}

Table III: Overall Successful Restoration of CSF Flow

\begin{tabular}{lcc}
\hline Location & No. of cases & Percentage \\
\hline Third ventricular NCC & $15 / 16$ & $93.75 \%$ \\
\hline Fourth ventricular NCC & $11 / 12$ & $91.67 \%$ \\
\hline Temporal Horn NCC & $0 / 1$ & $0 \%$ \\
\hline Septum Cavum NCC & $1 / 1$ & $100 \%$ \\
\hline
\end{tabular}

Table IV: Outcome of Endoscopic Interventions in Pediatric Age Group

Aim of surgery

\begin{tabular}{|c|c|c|c|c|}
\hline & \multicolumn{2}{|c|}{$3^{\text {ra }}$ Vent. $(n=5)$} & \multicolumn{2}{|c|}{$4^{\text {nn }}$ Vent. $(n=4)$} \\
\hline & Successful & Unsuccessful & Successful & Unsuccessful \\
\hline Diversion of CSF flow & $5(100 \%)$ & $0(0 \%)$ & $4(100 \%)$ & $0(0 \%)$ \\
\hline Excision/Decompression/visualization of cyst & $5(100 \%)$ & $0(0 \%)$ & $4(100 \%)$ & $0(0 \%)$ \\
\hline
\end{tabular}

\begin{tabular}{lcccc}
\hline & Successful & Unsuccessful & Successful & Unsuccessful \\
\hline Diversion of CSF flow & $5(100 \%)$ & $0(0 \%)$ & $4(100 \%)$ & $0(0 \%)$ \\
\hline Excision/Decompression/visualization of cyst & $5(100 \%)$ & $0(0 \%)$ & $4(100 \%)$ & $0(0 \%)$ \\
\hline
\end{tabular}

Table V: Outcome of Endoscopic Interventions in Adult Patients

Aim of surgery

\section{Aim of surgery}

\begin{tabular}{|c|c|c|c|c|}
\hline & \multicolumn{2}{|c|}{$3^{\text {ra }}$ Vent. $(n=11)$} & \multicolumn{2}{|c|}{$4^{\text {th }}$ Vent. $(n=4)$} \\
\hline & Successful & Unsuccessful & Successful & Unsuccessful \\
\hline Diversion of CSF flow & 10 (90.90\%) & $1(9.09 \%)$ & 7 (87.50\%) & $1(12.50 \%)$ \\
\hline
\end{tabular}

$3^{\text {rd }}$ Vent. $(n=11) \quad 4^{\text {th }}$ Vent. $(n=4)$

\section{Location}




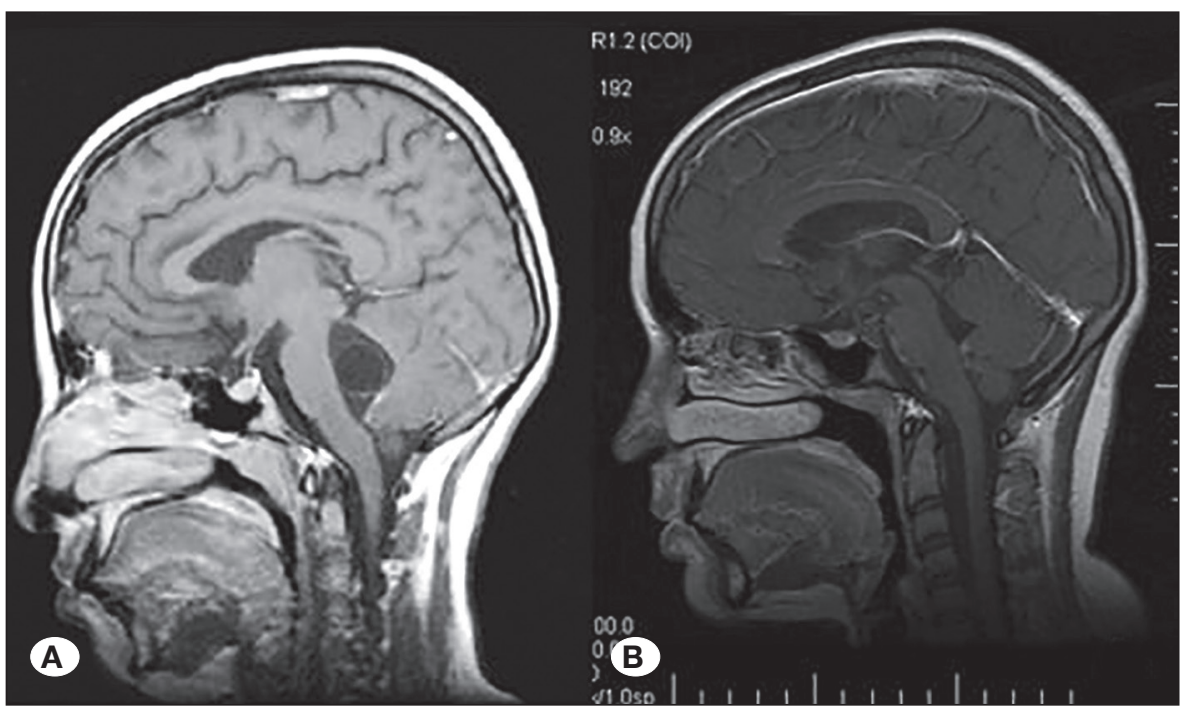

Figure 4: A) Preoperative, contrastenhanced T1-weighted, sagittal MRI scan showing mild enhancement of the wall of the cyst; B) contrast-enhanced, T1weighted, sagittal MRI scan of the same patient showing excision of cyst.

The third patient had a cyst in the temporal horn. In this patient, the cyst was decompressed, and endoscopic communication of the cyst with the remainder of the ventricular system was performed, but the patient did not improve and required a cysto-peritoneal shunt after three days.

Reasons for failures of excision, decompression and visualisation of cyst: In four of the patients, we were not able to visualise the cyst in the fourth ventricle. The possible explanation is either the migration of the cyst or the technical difficulty to navigate the fourth ventricle by using a rigid endoscope.

\section{Difficulties Encountered During Surgery}

Navigating the fourth ventricle: We encountered difficulty in removing the fourth ventricular cyst, for which we used an angiographic catheter with negative suction.

Removal of the cyst densely adherent to the ependymal lining: We encountered difficulty in removing the cyst, which was densely adhered. We proposed that a smaller and more precise instrument must be developed for successfully removing such a cyst.

\section{DISCUSSION}

Infestation of Taenia Solium causing cysticercosis is a prevalent health problem, especially in the developing world, and the most common parasitic infestation of the central nervous system is considered to be NCC. It has been attributed as the single most common cause of community-acquired active epilepsy; $26.3 \%$ to $53.8 \%$ active epilepsy cases in the developing world, including India and Latin America, are due to NCC (12).

Sotelo et al. observed the mean age to be 31.5 years, with a male-to-female ratio of 1.04:1, whereas in our series of 30 patients, the age ranged from 6 years to 85 years (mean, 28.63 years), with a and male-to-female ratio of 1.35:1 (17).

Intracranial hypertension was reported by Madrazo et al. in all their patients with intraventricular NCC, whereas seizures were present in $14 \%$ of such patients (10). The most common sign in their series was gait ataxia (57\%). We found that headache was the most common symptom (76.67\%), followed by nausea $(60 \%)$ and vomiting (40\%); the most common sign in our series was papilledema $(76.67 \%)$, followed by gait ataxia (20\%).

The incidence of hydrocephalus has been reported to be around $26 \%$ in cases of NCC (18). The treatment of hydrocephalus using VP shunt is associated with a high failure rate $(1,5,9)$. CSF diversion using endoscopic means has a success rate which varies from $40 \%$ to $100 \%(1,3,4,6,13-$ $16,20)$. In our series of 30 patients, we were able to perform endoscopic CSF diversion successfully in 27 (90\%) patients; the remaining three patients required shunt surgery due to failure of endoscopic CSF diversion. The reported success of endoscopic excision of the cyst ranges from $90 \%$ to $100 \%$ in different age groups. In our series, we were able to visualise the cyst successfully in 26 (86.67\%) patients and, out of these 26 patients, we were able to excise and decompress the cyst in $25(96.15 \%)$ patients.

Successful treatment of NCC by restoring CSF pathway and cyst excision was achieved in all patients by Suri et al. patients in the paediatric age group (6/6 patients). In our series, we had a similar success rate of $100 \%$ (9/9 patients) in both CSF diversion and excision of cyst in the paediatric age group (20).

\section{Transaqueductal Exploration}

Endoscopic exploration of the fourth ventricle has been addressed by few authors. Using an endoscope, Matula et al. have described three possible ways to reach the fourth ventricle: (1) via the third ventricle through the cerebral aqueduct; (2) from the lateral foramen of Luschka after opening the basal cistern; and (3) via the cerebellomedullary cistern through the foramen of Magendie (11).

Historical account of endoscopic exploration of the fourth ventricle by neurosurgeons is mostly using rigid endoscopes rather than flexible endoscopes. Gaab and Schroeder used rigid endoscopes through a frontal route for the treatment of 
aqueductal stenosis in 17 patients (7). These authors observed postoperative sequelae mainly associated with disturbances of ocular movement.

A right-transfrontal approach using a rigid endoscope was used to enter the lateral and third ventricle to remove fourthventricle cysts in three patients by Anandh et al. (1). Successful removal of cystic lesions was performed in all three patients with no deaths, although one patient experienced transient hemiparesis and ocular ptosis. Proano et al. negotiated a rigid endoscope up to of the opening of the cerebral aqueduct and aspirated the cysts using a no. 6 French catheter in a patient with fourth-ventricle NCC (13).

Flexible endoscope for exploration of the fourth ventricle in five cases has been reported by Bergsneider (3). He used a midline durotomy between the opisthion and the posterior arch of $\mathrm{C}-1$ to reach the fourth ventricle through the foramen of Magendie.

Many theoretical objections could be raised against the transaqueductal navigation of the fourth ventricle, but in light of our experience, this procedure was found to be relatively easy and harmless. The only neurological complication observed in our series was a mild diplopia due to transient third- and sixth-nerve paresis in a patient in whom aqueductoplasty was followed by patency of the fourth-ventricle outlets. The neurological deficit was almost certainly caused by the aqueductoplasty rather than by the transaqueductal passage of the endoscope.

All the patients of fourth-ventricle NCC in our series had a widely dilated aqueduct (10/12) the endoscope could be passed through to the fourth ventricle, and the cyst was visualised in $6 / 10$ patients. In cases of a mildly to moderately dilated aqueduct, only a catheter was passed transaqueductally after aqueductoplasty, to aspirate the cyst in $2 / 2$ patients.

Intraoperative cyst rupture causing postoperative ventriculitis is rare as Psarros et al. experienced that despite an $86 \%$ cyst intraoperative cyst rupture they experience no case of ventriculitis in their series. In our series, cyst rupture occurred in all $(26 / 26)$ cases, but none of the patients had postoperative ventriculitis (14).

Extreme bradycardia can be prevented by avoiding excessive use of irrigation fluid when dealing with fourth ventricle and intracranial hypertension cases (7). We do not completely block the outflow of fluid through the instrument port of the endoscope and, whenever required, block it only for a very short period while monitoring pulse and blood pressure. Even if episodes of significant bradycardia occurred, they immediately regressed after the withdrawal of small volumes of ventricular fluid.

\section{CONCLUSION}

We found that endoscopic CSF diversion in cases of intraventricular NCC is feasible and associated with a high success rate. Endoscopic CSF diversion in NCC-related hydrocephalus usually produces a long-term cure (In our study, over a mean period of 22.6 months, $90 \%$ of patients did not require any revision or other CSF diversion procedure).

In patients when CT/MRI raised suspicion of NCC but such suspicions were not confirmed by neuroendoscopy, the diagnosis of NCC could be confirmed by visualisation or biopsy. In patients with NCC-related hydrocephalus, cysts usually can be visualised during endoscopy. Intraoperative rupture or incomplete removal of the cyst has no negative impact on the outcome.

\section{REFERENCES}

1. Anandh B, Mohanty A, Sampath S, Praharaj SS, Kolluri S: Endoscopic approach intraventricular cysticercal lesions. Minim Invasive Neurosurg 44(4):194-196, 2001

2. Apuzzo ML, Dobkin WR, Zee CS, Chan JC, Giannotta SL, Weiss $\mathrm{MH}$ : Surgical considerations in treatment of intraventricular cysticercosis. An analysis of 45 cases. J Neurosurg 60(2):400407, 1984

3. Bergsneider M: Endoscopic removal of cysticercal cysts within the fourth ventricle. Technical note. J Neurosurg 91(2):340345, 1999

4. Bergsneider M, Holly LT, Lee JH, King WA, Frazee JG: Endoscopic management of cysticercal cysts within the lateral and third ventricles. J Neurosurg 92:14-23, 2000

5. Colli BO, Martelli N, Assirati JA Jr, Machado HR, de Vergueiro Forjaz S: Results of surgical treatment of neurocysticercosis in 69 cases. J Neurosurg 65: 309-315, 1986

6. Cuetter AC, Andrews RJ: Intraventricular neurocysticercosis: 18 consecutive patients and review of the literature. Neurosurg Focus 12(6):e5: 1-7, 2002

7. Gaab MR, Schroeder HW: Neuroendoscopic approach to intraventricular lesions. J Neurosurg 88: 496-505, 1998

8. Husain M, Jha DK, Rastogi M: Angiographic catheter: Unique tool for neuroendoscopic surgery. Surg Neurol 64(6):546-549, 2005

9. Kelly R, Duong DH, Locke GE: Characteristics of ventricular shunt malfunctions among patients with neurocysticercosis. Neurosurgery 50(4): 757-762, 2002

10. Madrazo I, Garcia-Renteria JA, Sandoval M, López Vega FJ: Intraventricular cysticercosis. Neurosurgery 12:148-152, 1983

11. Matula C, Reinprecht A, Roessler K, Tschabitscher M, Koos WT: Endoscopic exploration of the IVth ventricle. Minim Invasive Neurosurg 39:86-92, 1996

12. Prasad KN, Prasad A, Verma A, Singh AK: Human cysticercosis and Indian scenario: A review. J Biosci 33(4): 571-582, 2008

13. Proaño JV, Torres-Corzo J, Rodríguez-Della Vecchia R, Guizar-Sahagun G, Rangel-Castilla L: Intraventricular and subarachnoid basal cisterns neurocysticercosis: A comparative study between traditional treatment versus neuroendoscopic surgery. Childs Nerv Syst 25(11):14671475, 2009

14. Psarros TG, Coimbra C: Endoscopic third ventriculostomy for patients with hydrocephalus and fourth ventricular cysticercosis: A review of five cases. Minim Invasive Neurosurg 47(6): 346-349, 2004 
15. Psarros TG, Krumerman J, Coimbra C: Endoscopic management of supratentorial ventricular neurocysticercosis: Case series and review of the literature. Minim Invasive Neurosurg 46(6):331-334, 2003

16. Rangel-Castilla L, Serpa JA, Gopinath SP, Graviss EA, Diaz-Marchan P, White AC Jr: Contemporary neurosurgical approaches to neurocysticercosis. Am J Trop Med Hyg 80(3): 373-378, 2009

17. Sotelo J, del Brutto $\mathrm{OH}$ : Review of neurocysticercosis. Neurosurg Focus 12(6):1-7, 2002

18. Sotelo J, Guerrero V, Rubio F: Neurocysticercosis: A new classification based on active and inactive forms. A study of 753 such cases. Arch Inter Med 145(3): 442-445, 1985
19. Suri A, Goel RK, Ahmad FU, Vellimana AK, Sharma BS, Mahapatra AK: Endoscopic excision of intraventricular neurocysticercosis in children: A series of six cases and review. Childs Nerv Syst 24(2): 281-285, 2008

20. Suri A, Goel RK, Ahmad FU, Vellimana AK, Sharma BS, Mahapatra AK: Transventricular, transaqueductal scopein-scope endoscopic excision of fourth ventricular neurocysticercosis: A series of 13 cases and a review. J Neurosurg Pediatrics 1:35-39, 2008

21. Torrealba G, Del Villar S, Tagle P, Arriagada P, Kase CS: Cysticercosis of the central nervous system: Clinical and therapeutic considerations. J Neurol Neurosurg Psychiatry 47(8): 784-790, 1984 